\title{
Frequency of dietary supplements usage in the Saudi Arabian public and gym users
}

\author{
Muhammad Raihan Sajid', Lama Nasser Quraiba², Rahaf lyad Khames², Noara AlHusseini ${ }^{3}$, Haifa Alsheikh², Nabel \\ Rajab Basha², Saad Mansoor ${ }^{4}$, Aamir Omair ${ }^{5}$
}

\author{
'Department of pathology, Alfaisal University, Riyadh, Saudi Arabia. \\ ${ }^{2}$ Alfaisal University, Riyadh, Saudi Arabia. \\ ${ }^{3}$ Alfaisal University, Riyadh, Saudi Arabia. \\ ${ }^{4}$ Department of Medical education, Alfaisal University, Riyadh, Saudi Arabia. \\ ${ }^{5}$ Research Unit, Department of Medical Education, College of Medicine, King Saud bin Abdulaziz University for Health Sciences, Riyadh, Saudi Arabia. \\ Corresponding Author: Noara Alhusseini (E-mail: nalhusseini@alfaisal.edu ) \\ (Submitted: 25 August 2020 - Revised version received: 22 September 2020 - Accepted: 25 October 2020 - Published online: 26 December 2020)
}

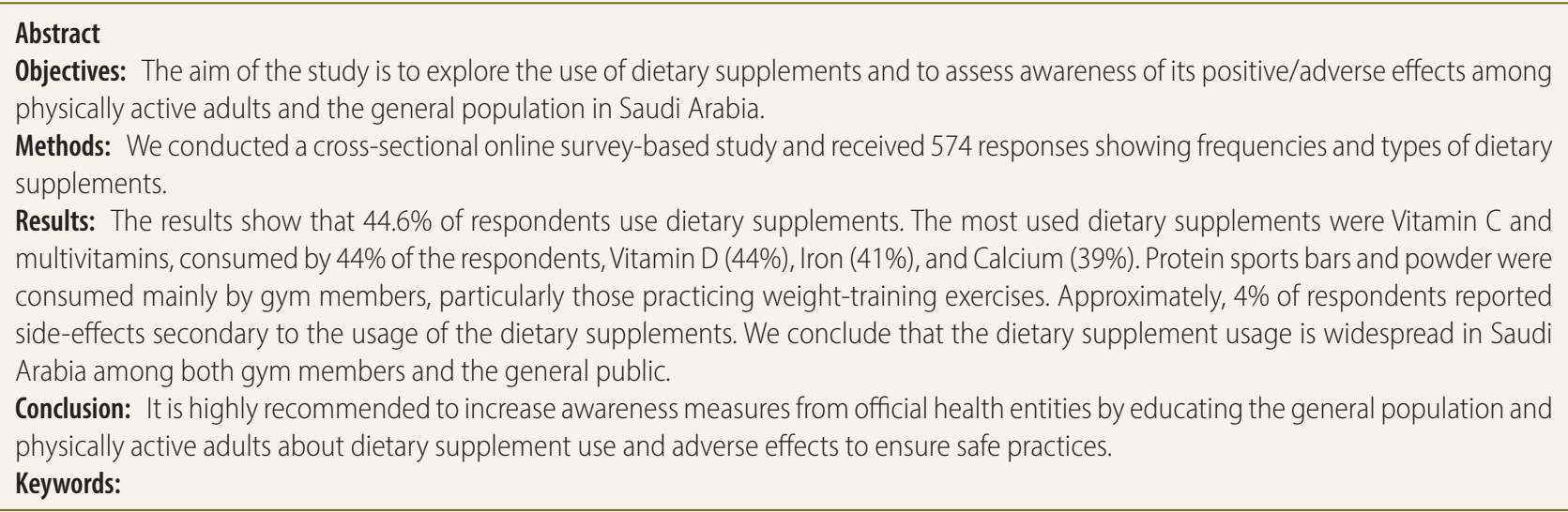

\section{Introduction}

Dietary supplements are considered as food products that contain dietary ingredients intended to supplement nutritional value to a diet. It encompasses specific vitamins, multivitamins, minerals, enzymes, amino acids, and herbs. ${ }^{1,2}$ As a balanced diet is essential for development and maintenance of the human body, dietary supplement usage has become commonplace to improve overall health and well-being, and to reduce the risk of certain diseases. Dietary supplements use has become very common in the US, Europe, and GCC countries. ${ }^{3}$

A previous study indicated that almost half of Saudi participants consumed dietary supplements. ${ }^{4}$ Another study reported $93.3 \%$ of Saudi athletes consumed supplements, ${ }^{5}$ while $76.6 \%$ of female Saudi college students reported consumption of dietary supplements. ${ }^{3}$ Furthermore, dietary supplements were reported to be used by $\sim 36 \%$ and $~ 24 \%$ of students in Saudi health and non-health colleges, respectively, while $62.3 \%$ of Saudi adults were reported to be supplement users or had used supplements at least once before. ${ }^{4}$

Such widespread usage has been attributed to increased availability of dietary supplements, and the belief that dietary supplements are more natural and safer to use compared to prescription medication. ${ }^{6}$ This rise in supplement use, however, is also associated with an increase in the adverse effects caused by supplement mis-/overuse, with studies reporting health complications (and fatalities in severe cases) due to overdose, drug-drug, and drug-disease interactions caused by supplement misuse., ${ }^{7,8}$. For example, excessive use of cholecalciferol and vitamin D may adversely affect soft tissues and kidney functions, ${ }^{9}$ while the medical management of cardiovascular diseases can be affected due to interactions between the supplement and various drugs used in the management of diseases. ${ }^{10}$

This study aimed to explore the use of dietary supplements among physically active adults and the general population in Saudi Arabia, and their awareness of positive/adverse effects of dietary supplements.

\section{Methods}

\section{Study Design}

This is a cross-sectional study using an online self-administered questionnaire. Questions included covered sociodemographic and lifestyle characteristics, perceived health status, dietary supplement use, and general awareness regarding adverse effects.

\section{Study Population}

Our target population was adults living in Saudi Arabia. Participants $<18$ and $>65$ years of age were excluded. Convenience sampling was utilized: assuming the estimated population of Saudi Arabia of 33.7 million, 95\% confidence interval, we calculated a target sample size of 384 . After excluding respondents under 18 and over 65 years of age, we analyzed a total of 574 responses. 


\section{Survey Tool (Questionnaire)}

Questions included covered sociodemographic and lifestyle characteristics, perceived health status, dietary supplement use, and general awareness regarding adverse effects.

We modified and designed our questionnaire from the previously used and validated surveys. ${ }^{11,12}$ Content validity was performed by an expert in the field. The survey was also translated and made available in Arabic as well as English. Face validity was performed by an Arabic language translation expert. The survey included questions aimed at assessing the knowledge, experience, and awareness of participants regarding dietary supplements in addition to demographic factors (such as age, gender, nationality, and level of education). We also queried the use, purpose, reasons, and duration of taking dietary supplements, as well as short-/long-term side effects, exercising, frequency of going to the gym, and type of supplement used among participants.

\section{Ethical Considerations}

Ethical approval was obtained from Alfaisal University Institutional Review Board (approval number IRB20026). Researchers abided by the rules and regulations of the Saudi National Committee of Bioethics and the Research Policies \& Procedures of Alfaisal University. No identifying data were collected to ensure anonymity and confidentiality. Access to the surveys' responses was limited to the investigators.

\section{Data Collection and Analysis}

The questionnaire was shared via electronic-social media platforms (Instagram, Twitter, and WhatsApp and work/personal emails). Data were extracted and analyzed using the SPSS Statistics 21 data analysis package. The descriptive statistics of mean, standard deviation, percentages, and frequencies were calculated. The Chi-square test was employed on categorical variables to examine associations. The significance was determined if the $p$-value was $<0.05$.

\section{Results}

A total of 636 respondents completed the questionnaire from different regions in Saudi Arabia, of which 574 respondents fit the inclusion criteria. The sociodemographic characteristics of the participants are summarized in Table 1 and their lifestyle choices are presented in Table 2 . The majority of the respondents were females (67\%), from the younger age group of $18-25$ years $(68 \%)$, most had a bachelor's degree or higher (68\%), and almost two-thirds were Saudi nationals (66\%). The Body Mass Index (BMI) grouping showed that $6 \%$ were underweight, while almost half were in the normal weight category (49\%); $28 \%$ overweight, and $15 \%$ obese among the respondents as shown in Table 1.

Table 2 shows that 163 (28\%) did not exercise, while most reported exercising 3-5 days per week (37\%) and another 14\% exercised 6-7 days per week. There were 199 (35\%) who were using some specific diet, while 264 (46\%) of the participants used dietary supplements in the last month. There were $106(18 \%)$ of the respondents who were members of a Gym (Table 3).
Table 1. Sociodemographic characteristics of the study participants $(n=574)$.

\begin{tabular}{llcc}
\hline Variable & & $\mathbf{n}$ & $\%$ \\
\hline Gender & Females & & \\
& Males & 383 & 66.5 \\
Age (years) & & 191 & 33.2 \\
& $18-25$ & & \\
& $26-45$ & 392 & 68.1 \\
& $>45$ & 156 & 27.1 \\
Educational level & 28 & 4.9 \\
& $\begin{array}{l}\text { High School / Diploma / } \\
\text { Intermediate } \\
\text { Bachelor's Degree / } \\
\text { Graduate }\end{array}$ & 183 & 31.7 \\
& & 391 & 67.8 \\
& & &
\end{tabular}

Nationality

$\begin{array}{lll}\text { Saudi } & 381 & 66.1 \\ \text { Non-Saudi } & 195 & 33.8\end{array}$

$\operatorname{BMI}\left(\mathbf{k g} / \mathrm{m}^{2}\right)$

\begin{tabular}{lcc}
$<18.5$ & 33 & 5.7 \\
$18.5-24.9$ & 284 & 49.3 \\
$25-29.9$ & 162 & 28.1 \\
$30+$ & 85 & 14.8 \\
Missing & 12 & 2.1 \\
\hline
\end{tabular}

Table 2. Lifestyle choices of respondents ( $\mathrm{N}=\mathbf{5 7 6}$ ).

N $\%$

Exercise

$\begin{array}{lcc}\text { No exercise } & 163 & 28.3 \\ \text { 1-2 days/week } & 122 & 21.2 \\ \text { 3-5 days/week } & 212 & 36.8 \\ \text { 6-7 days/week } & 79 & 13.7\end{array}$

Diet

$\begin{array}{lll}\text { Any specific diet } & 199 & 34.7 \\ \text { No specific diet } & 375 & 65.3\end{array}$

Use of dietary supplements

$\begin{array}{ccc}\text { Yes } & 264 & 44.6 \\ \text { No } & 317 & 55\end{array}$


Length of usage of dietary

supplements $(\mathrm{N}=264)$

$\begin{array}{lcc}<1 \text { month } & 40 & 6.9 \\ \text { 1-3 months } & 73 & 12.7 \\ >3 \text { months } & 151 & 26.2\end{array}$

Use of dietary supplements in the last month $(\mathrm{N}=264)$

$\begin{array}{lcc}\text { Daily } & 157 & 27.3 \\ \text { Weekly } & 82 & 14.2 \\ \text { Once a month } & 25 & 4.3\end{array}$

Gym members
Yes

No
There were 264 respondents who were using dietary supplements; the most common supplements were Vitamin C, Vitamin D, and multivitamins consumed by $44 \%$ of these 264 respondents. Other commonly used supplements included Iron (41\%) and Calcium (39\%). Protein sports bars and powder were consumed mainly by gym members, particularly those practicing weight-training exercises. A few respondents reported using other specific dietary supplements that included probiotics, Zinc, Magnesium, and Folic acid. There were $39 \%$ of the 264 respondents using dietary supplements who reported short- or long-term adverse effects directly resulting from supplement-use, while $4 \%$ reported side-effects secondary to the usage of the dietary supplements, including acne, constipation, bloating sensation, nausea, low appetite, change in urine color due to beta-carotene, dizziness, dependency, hair loss, erectile dysfunction, hypotension, changes in bowel movements, increased blood pressure, liver damage, anxiety, tremors, hypervitaminosis, and agitation.

The major sources of information regarding dietary supplements were identified as the internet (31\%), doctors/pharmacists (18\%), and friends/family (8\%). The most common reason for supplement use was to complete dietary/nutrient needs (34\%), while $16 \%$ of the participants used it for muscle building; another (15\%) reported use for medical recommendation/ prescription from a doctor. Other reported reasons included boosting immunity, enhancing performance (stamina), and improving memory. Of those who exercised, $60 \%$ reported exercising $1-2 \mathrm{~h} /$ session, while $38 \%$ reported exercising for $<1 \mathrm{~h}$. The most commonly reported type of workout was cardio (37\%) and weight training (34\%) exercises. Table 3 shows the association between the demographic variables and use of dietary supplements. There was a significantly higher proportion of females (48.8\%) than males $(36.8 \%)$ who reported using dietary supplements $(\mathrm{p}=0004)$. Respondents aged more than 45 years of age were more likely $(70.3 \%)$ to use dietary supplements $(\mathrm{p}=0.002)$ as compared to the younger respondents aged $18-25$ years $(41.1 \%)$ and $26-45$ years $(49.3 \%)$. Also, those with BMI greater than $30 \mathrm{~kg} / \mathrm{m}^{2}(48.2 \%)$ and $25-29.9 \mathrm{~kg} / \mathrm{m}^{2}(50.3 \%)$ were more likely to use dietary supplements as compared to those with BMI $<18.5$ (36.3\%) and $18.5-24.9 \mathrm{~kg} / \mathrm{m}^{2}(41.9 \%)$ $(\mathrm{p}=0.002)$. The use of dietary supplements was also higher in those who exercised (49.2\%) as compared to those who did not $(33.7 \%)(\mathrm{p}=0.001)$. Educational level was not significantly related to the use of dietary supplements $(\mathrm{p}=0.12)$. There was also no significant difference $(\mathrm{p}=0.13)$ in the use between Saudis and Non-Saudis (Table 3 ).

\begin{tabular}{|c|c|c|c|c|c|}
\hline & & $\mathbf{n}$ & $\begin{array}{l}\text { Use dietary supplement } \\
\text { n (\%) }\end{array}$ & $\begin{array}{l}\text { Do not use dietary supplement } \\
\qquad \mathbf{n}(\%)\end{array}$ & p-value \\
\hline \multirow[t]{2}{*}{ Gender } & Females & 383 & $187(48.8 \%)$ & $196(51.1 \%)$ & 0.004 \\
\hline & Males & 190 & 70 (36.8\%) & $120(63.2 \%)$ & \\
\hline \multirow[t]{2}{*}{ Educational level } & Bachelor / graduate & 391 & $168(42.9 \%)$ & $223(57.1 \%)$ & 0.12 \\
\hline & High school / diploma & 183 & 89 (48.6\%) & 94 (51.3\%) & \\
\hline \multirow[t]{3}{*}{ Age groups (yrs) } & $18-25$ & 391 & $161(41.1 \%)$ & 230 (58.9\%) & 0.002 \\
\hline & $26-45$ & 156 & 77 (49.3\%) & 79 (50.7\%) & \\
\hline & $>45$ & 27 & 19 (70.3\%) & $8(29.7 \%)$ & \\
\hline \multirow[t]{4}{*}{ BMI groups $\left(\mathbf{k g} / \mathrm{m}^{2}\right)$} & $<18.5$ & 33 & $12(36.3 \%)$ & $21(63.7 \%)$ & 0.002 \\
\hline & $18.5-24.9$ & 284 & $119(41.9 \%)$ & $165(58.1 \%)$ & \\
\hline & $25-29.9$ & 161 & $81(50.3 \%)$ & $80(49.7 \%)$ & \\
\hline & $>30$ & 85 & 41 (48.2\%) & $44(51.8 \%)$ & \\
\hline \multirow[t]{2}{*}{ Nationality } & Saudi & 382 & $178(46.6 \%)$ & $204(53.4 \%)$ & 0.13 \\
\hline & Non-Saudi & 192 & 79 (41.1\%) & $113(58.9 \%)$ & \\
\hline \multirow[t]{2}{*}{ Exercise } & Yes & 410 & $202(49.2 \%)$ & $208(50.7 \%)$ & 0.001 \\
\hline & No & 163 & $55(33.7 \%)$ & $108(66.2 \%)$ & \\
\hline
\end{tabular}


Table 4 presents the association between demographic variables with being on a specific diet. There was no difference with regards to gender $(\mathrm{p}=0.09)$, educational level $(\mathrm{p}=0.40)$, age group $(\mathrm{p}=0.62)$, and nationality $(\mathrm{p}=0.07)$. It was found that respondents who were overweight or obese (BMI $25 \mathrm{~kg} / \mathrm{m}^{2}$ and above) were more likely to be on a specific diet (42\%) as compared to those with BMI $<18.5 \mathrm{~kg} / \mathrm{m}^{2}$ (6\%) and those with normal BMI of 18.5 to $<25 \mathrm{~kg} / \mathrm{m}^{2}(31 \%)$ $(\mathrm{p}<0.001)$.

Table 5 also shows that there was no difference for exercising or not by gender $(\mathrm{p}=0.08)$, education level $(\mathrm{p}=0.32)$, and age group $\left(\mathrm{p}=0.69\right.$ ). Respondents who had $\mathrm{BMI}<18.5 \mathrm{~kg} / \mathrm{m}^{2}$
(48.5\%) or BMI $>30 \mathrm{~kg} / \mathrm{m}^{2}$ were less likely to exercise as compared to those with normal BMI $(76 \%)$ or BMI between 25 and $<30 \mathrm{~kg} / \mathrm{m}^{2}(74 \%)(\mathrm{p}=0.001)$. Also, Saudi nationals were more likely $(76 \%)$ to exercise as compared to non-Saudis $(63 \%)(\mathrm{p}=0.001)$

Table 5 shows no difference by gender in those who exercised $(p=0.08)$. Also, no statistically significant difference was seen in respondents who exercised based on their education levels $(p=0.31)$. Respondents with a higher BMI $\left(>30 \mathrm{~kg} / \mathrm{m}^{2}\right)$ were more likely to exercise as compared to those having a normal BMI $(p=0.001)$. Saudis were more likely to exercise as compared to the non-Saudi respondents $(p=0.001)$.

\begin{tabular}{|c|c|c|c|c|c|}
\hline & & $\mathbf{n}$ & $\begin{array}{c}\text { On specific diet } \\
\text { n (\%) }\end{array}$ & $\begin{array}{c}\text { No specific diet } \\
n(\%)\end{array}$ & p-value \\
\hline \multirow[t]{2}{*}{ Gender } & Females & 383 & $142(37.1 \%)$ & $241(62.9 \%)$ & 0.09 \\
\hline & Males & 190 & $57(30 \%)$ & $133(70 \%)$ & \\
\hline \multirow[t]{2}{*}{ Educational level } & Bachelor / graduate & 391 & $140(35.8 \%)$ & $251(64.2 \%)$ & 0.40 \\
\hline & High school / diploma & 183 & $59(32.2 \%)$ & $124(67.8 \%)$ & \\
\hline \multirow[t]{3}{*}{ Age groups (yrs) } & $18-25$ & 391 & $126(32.2 \%)$ & $265(67.8 \%)$ & 0.62 \\
\hline & $26-45$ & 156 & 70 (44.9\%) & $86(55.1 \%)$ & \\
\hline & $>45$ & 27 & $3(11.1 \%)$ & 24 (88.9\%) & \\
\hline \multirow[t]{4}{*}{ BMI groups (kg/m²) } & $<18.5$ & 33 & $2(6.1 \%)$ & 31 (93.9\%) & $<0.001$ \\
\hline & $18.5-24.9$ & 284 & 87 (30.6\%) & $197(69.4 \%)$ & \\
\hline & $25-29.9$ & 161 & 68 (42.2\%) & $93(57.8 \%)$ & \\
\hline & $>30$ & 85 & 36 (42.4\%) & $49(57.6 \%)$ & \\
\hline \multirow[t]{2}{*}{ Nationality } & Saudi & 382 & $141(36.9 \%)$ & $241(63.1 \%)$ & 0.07 \\
\hline & Non-Saudi & 192 & 58 (30.2\%) & $134(69.8 \%)$ & \\
\hline
\end{tabular}

\begin{tabular}{llcccc}
\hline \multicolumn{1}{l}{ Table 5. Association of demographic variables with exercise. } & \multicolumn{5}{l}{ Exercise } \\
\hline
\end{tabular}




\section{Discussion}

The findings of this study demonstrated a high prevalence of dietary supplement use in Saudi Arabia (45.8\%) and showed an association with certain demographics and lifestyle factors. Other studies have suggested that dietary supplement use has been very common on a global level. ${ }^{13}$ The prevalence of dietary supplement use varies globally, however, the findings indicate that it is relatively high in Saudi Arabia compared to other counties. A cross-sectional study used nationally representative data from the National Health and Nutrition Examination Survey in the United States indicated that over half of Americans used at least one type of dietary supplements during the previous month of the study. ${ }^{14}$ In addition, the prevalence of dietary supplement use among Pakistanis was $48.2 \%,{ }^{15}$ and $35.6 \%$ among college students in the United Arab Emirates, ${ }^{16}$ which confirm the findings of the high prevalence of dietary supplements use in general. Another cross-sectional study among Saudi population revealed that more than half of its participants used dietary supplements, which is similar to our findings. ${ }^{17}$ Moreover, a local study at Princess Nourah Bint Abdulrahman University in Riyadh also highlighted the finding of the high prevalence of dietary supplement use in Saudi as all its participants have used it at some point in time and $32.3 \%$ were using it at the time of the study. ${ }^{18}$ Alowais et al have suggested that increased awareness levels about health promotion and disease prevention contributed to the increased use of dietary supplements in many countries, ${ }^{17}$ which may justify the high prevalence of dietary supplement use in Saudi Arabia. However, a Chinese study revealed that only $24.2 \%$ of its participants consumed dietary supplements during the past year. ${ }^{19}$ The frequency of dietary supplement use in Saudi Arabia seems to be higher than other countries.

A comparison of educational levels (Bachelors and graduates vs high school and diploma holders) did not show a statistically significant difference regarding the use of dietary supplements. These findings match another study conducted in Saudi Arabia that found no association between dietary supplement use and the level of education. ${ }^{1}$ However, another study in Saudi Arabia found that dietary supplement use was more prevalent $(84.5 \%)$ among those with high educational levels. ${ }^{17}$ Also, another study indicated higher dietary supplement use among Chinese medical students (58.9\%) compared to non-medical students. ${ }^{19}$ The difference between these results and other studies can be due to the nature of this study, since the survey was distributed electronically and most participants (67.8\%) had higher education.

Since dietary supplements have been very common, sources of information about it vary. The major sources of information regarding dietary supplements identified by the participants were internet, doctors, or pharmacists, and friends, family, or relatives which is in concordance with findings of other studies. ${ }^{17}$ However, Rogza et al. found that physicians were the most frequent source of information for dietary supplement use, which is safer for consumers unlike unreliable sources like Internet. ${ }^{20}$ Though only $15 \%$ of the participants used dietary supplements due to a medical recommendation/prescription from a doctor, it is recommended to increase awareness measures from official health entities by educating the general population and physically active adults about dietary supplement use and adverse effects to ensure safe practices.
The findings show that the most used dietary supplements were Vitamin $C$ and multivitamins or both, unlike another Saudi-based study among females that showed that cod liver oil, Omega 3, multivitamins, ginseng, and vitamin A to be most commonly used supplements. The difference could be a result of limiting the study to college females only as their reason for dietary supplement use was to maintain healthy hair, unlike this study that included both males and females up to 65 years old. ${ }^{3}$ Similarly, a study conducted among Saudi females suggested that the primary reason for using dietary supplements was for aesthetic reasons. ${ }^{18}$

Other commonly used supplements in this study were: Vitamin D, Iron, and Calcium. Protein sports bars and protein powder were consumed mainly by gym members, particularly those practicing weight-training exercises. A few participants reported using other specific dietary supplements that include probiotics, Zinc, Magnesium, and finally folic acid. However, Jawadi et al found that most commonly used supplements among active adults who go to the gym in Saudi were whey protein, amino acids, multivitamins, creatinine, and Omega 3 to improve body shape, ${ }^{21}$ which is slightly similar to the findings in this study as $16 \%$ of participants used it for muscle building. Other reported reasons included boosting immunity, enhancing performance (stamina), and improving memory.

Athletes use dietary supplements for various reasons such as maintenance of good health and improving micronutrient deficiencies. Maintaining a balanced meal can be a challenge, therefore, dietary supplements replace inadequate energy and macronutrient intake. ${ }^{13}$ This study mirrors the findings as the most common reason for using dietary supplements reported by the participants was completing dietary/nutrient needs.

The results indicate that almost $40 \%$ of the responses replied in affirmative regarding dietary supplements having short- or long-term adverse effects. Significantly just $4 \%$ of respondents reported side-effects secondary to the usage of the dietary supplements. Another study conducted among Saudis also revealed that dietary supplement consumers (75\%) were aware of its adverse effects. ${ }^{4}$ In contrast, another study in India showed that only $16.9 \%$ of dietary supplement users felt that regular use results in side-effects. ${ }^{22}$

Some of the adverse effects reported included acne, constipation, bloating sensation, nausea, low appetite, change in urine color due to beta carotene, dizziness, dependency, hair loss, erectile dysfunction, hypotension, changes in bowel movements, increased blood pressure, liver damage, anxiety, tremors, hypervitaminosis, and agitation. Some of the adverse effects including diarrhea, constipation, stomachache, headache, nausea, and vomiting have been reported among Japanese adults from using dietary supplements. However, only just under $10 \%$ of them have reported the symptoms due to the inability to link the cause and effect relationship of these adverse effects. ${ }^{23}$

The results showed that respondents who exercised were more likely to use dietary supplements. A cross-sectional study among Saudi females mirrors our findings as it showed that more physical activity was significantly positively associated with dietary supplements use. ${ }^{3}$ While another study in Saudi Arabia showed that dietary supplement users believed that its use is most needed among pregnant women and during recovery from diseases. ${ }^{17}$ Since this study sample included physically active participants, this difference can be justified by the type of dietary supplements and the purpose of its use. 


\section{Study limitations}

Since our study was conducted during coronavirus COVID-19 pandemic, all sports activities including gyms were closed due to social distancing and quarantine regulations, which might have impacted physical activity levels and dietary supplement use. Therefore, this factor can affect the generalizability of our study. In addition, due to the nature of the cross-sectional studies, causal inferences cannot be achieved. Moreover, recall bias in the type and frequency of supplement use may be present. Selection bias is another limitation given that only people with internet access were included in our study.

\section{Conclusion}

The dietary supplement usage is widespread in Saudi Arabia among both gym members and general public. The incidence of reported adverse effects is low as compared to other published studies. Since there are many dietary supplements available, future studies should be conducted to assess different types of dietary supplements and its adverse effects in Saudi Arabia. In addition, it is highly recommended to increase awareness measures from official health entities by educating the general population and physically active adults about dietary supplement use and adverse effects to ensure safe practices.

\section{Conflicts of Interests}

Authors report no conflict of interests.

\section{References}

1. Alfawaz HA, Krishnaswamy S, Al-Faifi L, Atta HA Bin, Al-Shayaa M, Alghanim $S A$, et al. Awareness and attitude toward use of dietary supplements and the perceived outcomes among saudi adult male members of fitness centers in Saudi Arabia. Int J Sport Nutr Exerc Metab. 2018.

2. Muwonge H, Zavuga R, Kabenge PA, Makubuya T. Nutritional supplement practices of professional Ugandan athletes: A cross-sectional study. J Int Soc Sports Nutr. 2017.

3. Alfawaz H, Khan N, Alfaifi A, Shahrani FM, Al Tameem HM, Al Otaibi SF, et al. Prevalence of dietary supplement use and associated factors among female college students in Saudi Arabia. BMC Womens Health. 2017.

4. Algaeed H, AlJaber M, Alwehaibi A, AlJaber L, Arafah A, Aloyayri M, et al. General public knowledge and use of dietary supplements in Riyadh, Saudi Arabia. J Fam Med Prim Care. 2019.
5. Aljaloud SO, Ibrahim SA. Use of dietary supplements among professional athletes in Saudi Arabia. J Nutr Metab. 2013.

6. Dennehy CE, Tsourounis C, Horn AJ. Dietary supplement-related adverse events reported to the California Poison Control System. Am J Heal Pharm. 2005.

7. Deuster PA. Dietary supplements and adverse events. Mil Med. 2020.

8. Timbo BB, Ross MP, Mccarthy PV., Lin CTJ. Dietary supplements in a national survey: Prevalence of use and reports of adverse events. J Am Diet Assoc. 2006.

9. Drüeke TB, Massy ZA. Role of vitamin D in vascular calcification: Bad guy or good guy? Nephrology, dialysis, transplantation : official publication of the European Dialysis and Transplant Association - European Renal Association. 2012.

10. Dwyer JT, Coates PM, Smith MJ. Dietary supplements: Regulatory challenges and research resources. Nutrients. 2018.

11. Lieberman HR, Stavinoha TB, McGraw SM, White A, Hadden LS, Marriott BP. Use of dietary supplements among active-duty US Army soldiers. Am J Clin Nutr. 2010.

12. Lieberman HR, Marriott BP, Williams C, Judelson DA, Glickman EL, Geiselman PJ, et al. Patterns of dietary supplement use among college students. Clin Nutr. 2015.

13. Maughan RJ, Burke LM, Dvorak J, Larson-Meyer DE, Peeling P, Phillips SM, et al. IOC consensus statement: Dietary supplements and the highperformance athlete. Br J Sports Med. 2018.

14. Kantor ED, Rehm CD, Du M, White E, Giovannucci EL. Trends in dietary supplement use among US adults from 1999-2012. JAMA - J Am Med Assoc. 2016.

15. Naqvi AA, Ahmad R, Zehra F, Yousuf R, Kachela B, Nehal Nadir M. Dietary supplement use among students of pharmacy colleges in the City of Karachi, Pakistan: Prevalence, opinions, and attitudes. J Diet Suppl. 2019.

16. Radwan H, Hasan HA, Ghanem L, Alnajjar G, Shabir A, Alshamsi A, et al. Prevalence of dietary supplement use and associated factors among college students in the United Arab Emirates. J Community Health. 2019.

17. Alowais M, Selim ME-H. Knowledge, attitude, and practices regarding dietary supplements in Saudi Arabia. J Fam Med Prim Care. 2019.

18. Altamimi JZ. Awareness of the consumption of dietary supplements among students in a University in Saudi Arabia. J Nutr Metab. 2019.

19. Liu H, Yang Y, Xu D, Xia H, Pan D, Wang S, et al. Investigation and comparison of nutritional supplement use, knowledge, and attitudes in medical and non-medical students in China. Nutrients. 2018

20. Tindle HA, Wolsko P, Davis RB, Eisenberg DM, Phillips RS, McCarthy EP. Factors associated with the use of mind body therapies among United States adults with musculoskeletal pain. Complement Ther Med. 2005.

21. Jawadi AH, Addar AM, Alazzam AS, Alrabieah FO, Al Alsheikh AS, Amer RR, et al. Prevalence of dietary supplements use among gymnasium users. J Nutr Metab. 2017.

22. Joseph N, Kumar A, Singh H, Shaheen M, Das K, Shrivastava A. Nutritional supplement and functional food use among medical students in India. J Diet Suppl. 2018.

23. Chiba T, Sato Y, Kobayashi E, Ide K, Yamada H, Umegaki K. Behaviors of consumers, physicians and pharmacists in response to adverse events associated with dietary supplement use. Nutr J. 2017.

This work is licensed under a Creative Commons Attribution-NonCommercial 3.0 Unported License which allows users to read, copy, distribute and make derivative works for non-commercial purposes from the material, as long as the author of the original work is cited properly. 